OPEN ACCESS

Edited by:

Gustavo Henrique Goldman, University of São Paulo, Brazil

Reviewed by:

Ramganesh Selvarajan,

University of South Africa,

South Africa

Errol Duncan Cason,

University of the Free State,

South Africa

*Correspondence:

Mengzhi Wang

mengzhiwangyz@126.com

Yuqing Gong

gyq0814@sina.com

Specialty section:

This article was submitted to

Fungi and Their Interactions,

a section of the journal

Frontiers in Microbiology

Received: 29 March 2021

Accepted: 19 July 2021

Published: 12 August 2021

Citation:

Zhen Y, Wang M, Gu Y, Yu X, Shahzad K, Xu J, Gong Y, Li P and Loor JJ (2021) Biosorption of Copper in Swine Manure Using Aspergillus and Yeast: Characterization and lts

Microbial Diversity Study.

Front. Microbiol. 12:687533. doi: 10.3389/fmicb.2021.687533

\section{Biosorption of Copper in Swine Manure Using Aspergillus and Yeast: Characterization and Its Microbial Diversity Study}

\author{
Yongkang Zhen ${ }^{1}$, Mengzhi Wang ${ }^{1,2 *}$, Yalan $\mathrm{Gu}^{1}$, Xiang Yu${ }^{1}$, Khuram Shahzad ${ }^{3}$, Jun $X u^{4}$, \\ Yuqing Gong ${ }^{5 *}$, Peizhen Li ${ }^{5}$ and Juan J. Loor ${ }^{6}$ \\ ${ }^{1}$ College of Animal Science and Technology, Yangzhou University, Yangzhou, China, ${ }^{2}$ State Key Laboratory of Sheep \\ Genetic Improvement and Healthy Production, Xinjiang Academy of Agricultural and Reclamation Sciences, Shihezi, China, \\ ${ }^{3}$ Department of Biosciences, COMSATS University Islamabad, Islamabad, Pakistan, ${ }^{4}$ Institute for Quality and Safety \\ and Standards of Agricultural Products Research, Jiangxi Academy of Agricultural Sciences, Nanchang, China, ${ }^{5}$ Jiangsu \\ Provincial Station of Animal Husbandry, Nanjing, China, ${ }^{6}$ Mammalian Nutrition Physiology Genomics, Division of Nutritional \\ Sciences, Department of Animal Sciences, University of Illinois at Urbana-Champaign, Urbana, IL, United States
}

Dietary copper supplementation in the feed of piglets generally exceeds 250$800 \mathrm{mg} / \mathrm{kg}$, where a higher quantity (>250 mg/kg) can promote growth and improve feed conversion. Despite the reported positive effects, $90 \%$ of copper is excreted and can accumulate and pollute the soil. Data indicate that fungi have a biosorptive capacity for copper. Thus, the objectives of the present experiment were to study the effects of adding different strains of fungi on the biosorptive capacity for copper in swine manure and to evaluate potential effects on microbiota profiles. Aspergillus niger (AN), Aspergillus oryzae (AO), and Saccharomyces cerevisiae (SC) were selected, and each added $0.4 \%$ into swine manure, which contain $250 \mathrm{mg} / \mathrm{kg}$ of copper. The incubations lasted for 29 days, and biosorption parameters were analyzed on the 8th (D8), 15th (D15), 22nd (D22), and 29th (D29) day. Results showed that after biosorption, temperature was $18.47-18.77^{\circ} \mathrm{C}$; $\mathrm{pH}$ was $6.33-6.91$; and content of aflatoxin B1, ochratoxin A, and deoxynivalenol were low. In addition, residual copper concentration with AN was the lowest on D15, D22, and D29. The copper biosorption rate was also highest with AN, averaging $84.85 \%$ on D29. Biosorption values for AO reached $81.12 \%$ and for SC were lower than $80 \%$. Illumina sequencing of 16 S and ITS rRNA gene revealed that fungal treatments reduced the diversity and richness of fungal abundance, but had no effect on bacterial abundance. Unknown_Marinilabiliaceae, Proteiniphilum, Tissierella, and Curvibacter were the dominant bacteria, while Aspergillus and Trichoderma were the dominant fungi. However, the added strain of S. cerevisiae was observed to be lower than the dominant fungi, which contained less than $0.05 \%$. The Kyoto Encyclopedia of Genes and Genomes (KEGG) pathway enrichment predicted via PICRUSt2 that there were bacterial genes potentially related to various aspects of metabolism and environmental information processing. Overall, data indicated that Aspergillus can provide microbial materials for adsorption of copper.

\footnotetext{
Keywords: Aspergillus, swine manure, copper, microbial biosorption, 16S and ITS rRNA sequence
} 


\section{INTRODUCTION}

It has been demonstrated through several studies that copper can accelerate the growth and development of livestock (Zhi et al., 2020), including broilers (Ewing et al., 1998), goats (Solaiman et al., 2001), and rabbits (Skrivanova et al., 2001). This trace mineral improves growth and feed conversion rates of piglets, thus enhancing production performance (Stahly et al., 1980; Apgar et al., 1995). At a mechanistic level, high copper stimulates the synthesis and secretion of growth-promoting hormonerelated factors in piglets (Yang et al., 2011). Other studies revealed that high dietary copper increases activities of various digestive enzymes in the gastrointestinal tract of piglets, including pepsin and trypsin, accelerates gastrointestinal peristalsis, and improves feed digestibility (Luo and Dove, 1996). High dietary copper also increases the activity of antioxidant enzymes and accelerates gastric acid secretion in piglets, which is beneficial to health. Copper sources in animal feed include mainly copper sulfate, basic copper chloride, copper citrate, and chelated copper (Armstrong et al., 2000; Zhai et al., 2006). Thus, inclusion of high copper levels in feed has become a common practice, with compound feeds for growing pigs containing more than 250-1,000 mg/kg (Nicholson et al., 1999; Eneji et al., 2001). However, almost $90 \%$ of the ingested copper is released into the soil through manure because animals have a low absorption capacity for this mineral. This leads to the accumulation of copper in the soil.

Long-term use of manure and fertilizers with high copper levels increases the risk of soil pollution, which may further cause water and plant pollution and even harm human health (Jondreville et al., 2003; Bai et al., 2015). In order to reduce the risk of high copper excretion into feces, soil, and water, in 2018, the Official Journal of the European Union published a document (No. EU2018/1039) detailing the standards for the use of copper as a feed additive for all farmed animals. It decreased the copper limit for suckling pigs to $150 \mathrm{mg} / \mathrm{kg}$ and piglets to $100 \mathrm{mg} / \mathrm{kg}$, which represented a reduction of 11.8 and $41.2 \%$ compared with previous values, respectively. The revision of the standard reflected a serious approach to ensuring environmental protection in the livestock industry. In fact, in order to continue developing efficient animal husbandry approaches to reduce pollution, there is a need for continued research to ensure sustainable development and environmental protection.

High copper removal technology for soil and sewage has been developed. The passivation of heavy metals (Wuana and Okieimen, 2011) using agents such as lime, phosphorous lime, biochar, sodium silicate, and attapulgite bar can reduce the bioavailability of soil copper (Zhang et al., 2011; Hale et al., 2012; Cui et al., 2016; Jones et al., 2016). Removal of copper from wastewater includes mainly physical, chemical precipitation, and biological methods. Biotechnological methods pertain to removal of copper via biological metabolism, adsorption, repair, and flocculation, mainly through cell surface adsorption and intracellular aggregation (Javanbakht et al., 2014; Osmanlioglu, 2018; Virolainen et al., 2019). Compared with the treatment in soil and sewage, treatment technologies for high copper in manure have been less studied.
Fungi such as Aspergillus, Cladosporium, and Saccharomyces can adsorb and remove copper and have been used previously (Chang et al., 1997; Sayer and Gadd, 1997; Gunasundari and Kumar, 2017). The process of biosorption is complex, with the first step being adsorption of copper to the active groups such as hydroxyl $(-\mathrm{OH})$, carboxyl $(-\mathrm{COOH})$, amino $\left(-\mathrm{NH}_{2}\right)$, and sulfhydryl $(-\mathrm{SH})$ on fungal cell walls and membranes (Dursun, 2006; Noormohamadi et al., 2019). In addition, polysaccharides on the cell wall secrete active groups and chitosan, further enhancing the adsorption capacity of copper (ZabochnickaSwiatek and Krzywonos, 2014). Part of copper will enter the cell when the adsorption approaches saturation, and $\mathrm{Cu}^{2+}$ is reduced to $\mathrm{Cu}^{+}$by FRE1/2 gene and then transported into the cell through the copper transporter gene CTR1/3 (Dancis et al., 1994; Georgatsou et al., 1997). Then, a copper chaperone protein will specifically bind to copper and transport it to various organelles, mainly through three pathways: (i) copper transporter cytochrome oxidase 17 (Cox17) receives $\mathrm{Cu}^{+}$transported by CTR and sends it to the mitochondrial inner membrane (Heaton et al., 2000); (ii) the Atx1 transfers copper to Ccc2p and binds to FET3p on the reverse side of the Golgi apparatus (Arnesano et al., 2001); and then (iii) copper chaperone CCS (copper chaperone for Sod1p) transports copper to Sod1p in cellular fluid to clean up superoxide ions (Schmidt et al., 1999). Furthermore, when copper is in excess, the glutathione system in fungal cells is activated to prevent copper stress (Zhu et al., 1999). Production of metallothionein and phytochelatins also aids in copper detoxification (Inouhe et al., 1996; Liti et al., 2009).

Previous reports indicated that Saccharomyces cerevisiae (Sun et al., 2016), Aspergillus oryzae (Long et al., 2017), and Aspergillus niger (Wang J.Y. et al., 2016) have a high efficiency for copper biosorption in water. Furthermore, they have a high degree of commercialization, are easy to reproduce, and are non-toxic. Because of these reasons, the above three strains were selected for testing the copper-absorbing capacity in swine manure. In addition, the sequencing data will reveal the interaction relationship between fungi and bacteria, and their superiority strains will be screened for post-production materials of copper adsorbent.

\section{MATERIALS AND METHODS}

\section{Selection of Fungi, Swine Manure, and Biosorption Conditions}

Saccharomyces cerevisiae (SC), A. oryzae (AO), and A. niger (AN) were selected based on previous reports (Sun et al., 2016; Wang J.Y. et al., 2016; Long et al., 2017). Fungi were purchased from a local commercial company at $>5$ billion/g spores per fungi strain, cultured in media, and the spore concentration in the final suspensions determined by counting in a hemocytometer (Wang J.Y. et al., 2016). The experiment included a control (CON), SC, AO, and AN treatments, each replicated three times. Each treatment consisted of addition of $0.4 \%$ fungal spores to swine manure $(4 \mathrm{~g} / \mathrm{kg})$ to ensure a density greater than $10^{7}$ cells/g, with a $10 \times$ density of liquid adsorption medium (Sun et al., 2019). Twenty-five kilograms 
fresh swine manure was collected from an experimental farm in which pigs were fed with full grain feed. Animals were free from clinical disease. The original copper concentration determined by an atomic absorption spectrophotometer (AAS, PinAAcle 900F, PerkinElmer Corporation, Waltham, MA, United States) in swine manure was $9.6 \mathrm{mg} / \mathrm{kg}$ (Nyantakyi et al., 2019). A total of $15.10 \mathrm{~g}$ copper sulfate was added to $10 \mathrm{~L}$ of deionized water, mixed, and transferred to $25 \mathrm{~kg}$ of manure to give a final copper content of $250 \mathrm{mg} / \mathrm{kg}$. The manure was then divided into 12 subsamples, and $0.4 \%$ of each fungi strain mixed in. All vessels were then covered with a shielding net to avoid light and the biosorption simulated. The incubations lasted for 29 days, and biosorption parameters were analyzed on the 8th (D8), 15th (D15), 22nd (D22), and 29th (D29) day.

\section{Temperature, $\mathrm{pH}$, and Mycotoxin Content}

Manure samples on the final biosorption state (D29) were collected to determine the temperature, $\mathrm{pH}$, and mycotoxin levels. During sampling, an alcohol thermometer was inserted into the manure at $5-10 \mathrm{~cm}$ to determine the temperature. Then, $9 \mathrm{~mL}$ distilled water was added into $1 \mathrm{~g}$ of manure and homogenized for $30 \mathrm{~s}$ to determine $\mathrm{pH}$ using a calibrated $\mathrm{pHS}$ $3 \mathrm{C}$ precision $\mathrm{pH}$ meter (Leimeg, Shanghai, China). Lastly, the concentration of mycotoxin was determined using the following methods according to manufacturer's protocols: aflatoxin B1 test kit (CNW, SNEQ-C110119, Düsseldorf, Germany), ochratoxin A test kit (CNW, SNEQ-C11019, Düsseldorf, Germany), and deoxynivalenol test kit (CNW, SNEQ-C11002, Düsseldorf, Germany).

\section{Residual Copper Concentration and Copper Biosorption Rate}

Air-dried swine manure samples were weighed to determine residual copper concentration and copper biosorption rate according to published protocols (Park et al., 2011; Wang W.Y. et al., 2016; Meier et al., 2017). Briefly, $5 \mathrm{~g}$ of air-dried samples was weighed, $20 \mathrm{~mL}$ deionized water was added, and the mixture was vortexed for $30 \mathrm{~s}$. Then, samples were centrifuged at 8,000 rpm for $10 \mathrm{~min}$, and the supernatant on the upper layer was then carefully absorbed and collected. This fraction contained the dissolved ionic copper from manure. Fungi in the middle layer were carefully removed and the precipitate at the bottom was collected. The supernatant was used to dissolve the manure precipitate again, repeating the above steps and washing the precipitate with deionized water. The mass of copper ions dissolved in swine manure was measured by AAS (PinAAcle 900F, PerkinElmer Corporation, Waltham, MA, United States). The sediment was dried at $60^{\circ} \mathrm{C}$ for $48 \mathrm{~h}$ for determining copper concentrations according to the published protocol (Nyantakyi et al., 2019). Residual copper concentration was the sum of the concentration of copper in supernatant and sediment. Copper biosorption rate was calculated by the following formula:

$$
R \%=\frac{C_{0}-C_{i}}{C_{0}} \times 100 \%
$$

where $R \%$, copper biosorption rate; $C_{0}$, initial copper concentration; and $C_{i}$, residual copper concentration (including the mass of copper in the supernatant and cleaning fluid).

\section{DNA Extraction, Illumina MiSeq Sequencing, and Data Processing}

Total microbial DNA from manure samples in the CON, SC, $\mathrm{AO}$, and AN groups was extracted using the fecal genome extraction kit (DP328, Tiangen Biotech Co., Ltd., Beijing, China) according to manufacturer's protocols. The concentration and purity of total DNA $\left(\mathrm{OD}_{260 / 280}\right.$ and $\left.\mathrm{OD}_{260 / 230}\right)$ were determined by the NanoDrop spectrophotometer (Thermo Fisher Scientific, Waltham, MA, United States). The integrity of DNA was determined by agarose gel electrophoresis.

Bacterial and fungal communities and diversities were determined by high-throughput sequencing with the Illumina Novaseq-PE250 platform at Genepioneer Biotechnologies Co., Ltd., Nanjing, China. Amplification of the V3-V4 region of bacterial rRNA genes was completed using the universal primers (319F: 5'-ACTCCTACGGGAGGCAGCAG-3'; 806R: 5' GGACTACHVGGGTWTCTAAT-3') (Yang et al., 2019). The ITS2 region of fungal rRNA genes was amplified with ITS3 and ITS4 primer (ITS3F: 5'-GCATCGATGAAGAACGCAGC3'; ITS4R: 5'-TCCTCCGCTTATTGATATGC-3') (Essel et al., 2019). The 16S and ITS rRNA gene amplicon sequencing data generated during the current study were submitted to NCBI under BioProject PRJNA704785.

Paired-end reads generated from Illumina platforms were processed and merged using FLASH software (v1.2.7) (Magoc and Salzberg, 2011). Then, high-quality clean sequence tags were obtained by removing lower quality and shorter lengths. Subsequently, the Uparse pipeline of Usearch (v7.1) software (Edgar, 2013) was employed to cluster all reads from each sample into operational taxonomic units (OTUs) at a 97\% sequence similarity level. Representative sequences of each OTU were screened for further annotation. Taxonomic information was compared to the SILVA database (Release 115) (Quast et al., 2013) for bacterial 16S rRNA genes, while UNITE v8.0 database (Nilsson et al., 2019) was used for annotating fungal ITS rRNA gene reads. Taxonomies were grouped at the phylum, class, order, family, and genus levels. The bacterial and fungal community richness (Chaol and ACE indexes), diversity (Shannon and Simpson indexes), and Good's coverage were calculated with QIIME (v1.9.1) software (Caporaso et al., 2010). Linear discriminant analysis effect size (LEfSe) was used to elucidate bacterial and fungal genus classification taxa that were associated with each fungal treatment (Segata et al., 2011). LEfSe was calculated using the Galaxy web platform ${ }^{1}$, and only linear discriminant analysis (LDA) scores $\geq 2$ were listed. The FAPROTAX software (Louca et al., 2016) was used to predict ecological functions of microbial communities. In addition, microbial community functions were predicted by PICRUSt2 (v1.1.0) based on high-quality sequences and annotated in the Kyoto Encyclopedia of Genes and Genomes (KEGG) database (Langille et al., 2013).

\footnotetext{
${ }^{1}$ https://huttenhower.sph.harvard.edu/galaxy/
} 


\section{Statistical Analysis}

Temperature, $\mathrm{pH}$, mycotoxins, residual copper concentration, copper biosorption rate, and alpha diversity index were subjected to the one-way ANOVA using SPSS 13.0 software. The line chart of residual copper concentration and copper biosorption rate was made by GraphPad Prism 6.0 software. Bacterial and fungal taxa analyses were plotted using the GraphPad Prism 6.0 software based on the modified OTU data. Only those taxa with an abundance $>1 \%$ of the total community in at least one treatment were included. The Venn diagram was analyzed using the R package "VennDiagram.” Pearson's correlation analysis was carried out by R package "ggplot2," "corrplot," and "pheatmap." The bubble diagram of pathway enrichment analysis was made using the R package "ggplot2." The R version was 4.0.2, and R packages were described previously (Chen and Boutros, 2011; Li et al., 2021). Significance was declared at $P<0.05$.

\section{RESULTS}

\section{Temperature, $\mathrm{pH}$, and Mycotoxin Concentrations}

Temperature, $\mathrm{pH}$, aflatoxin B1, ochratoxin, and deoxynivalenol of final biosorption state are reported in Table 1. The $\mathrm{pH}$ of CON and AN was significantly higher than that of SC $(P<0.05)$. The concentration of aflatoxin $\mathrm{B} 1$ and deoxynivalenol of CON was significantly higher than that of SC, AO, and AN $(P<0.05)$. No significant differences $(P>0.05)$ were observed in temperature and ochratoxin A among treatments. The temperature was close to the fermentation room temperature, and $\mathrm{pH}$ values were near the original $\mathrm{pH}$ of manure.

\section{Residual Copper Concentration and Biosorption Rate}

The residual copper concentration and biosorption rate in swine manure on D8, D15, D22, and D29 are shown in Figure 1. Compared with different biosorption periods, except for CON, there were significant differences in copper biosorption rate and residual copper concentration in feces among the three treatments $(P<0.05)$. When studying the copper biosorption

TABLE 1 | The temperature, $\mathrm{pH}$, aflatoxin $\mathrm{B} 1$, ochratoxin, and deoxynivalenol of final state.

\begin{tabular}{|c|c|c|c|c|c|c|}
\hline \multirow[t]{2}{*}{ Items } & \multicolumn{4}{|c|}{ Treatments } & \multirow[t]{2}{*}{ SEM } & \multirow[t]{2}{*}{$P$-value } \\
\hline & CON & SC & AO & AN & & \\
\hline Temperature, ${ }^{\circ} \mathrm{C}$ & 18.48 & 18.47 & 18.57 & 18.77 & 0.13 & 0.883 \\
\hline $\mathrm{pH}$ & $6.91^{\mathrm{a}}$ & $6.33^{b}$ & $6.60^{a b}$ & $6.82^{a}$ & 0.09 & 0.037 \\
\hline Aflatoxin B1, $\mu \mathrm{g} / \mathrm{kg}$ & $3.33^{a}$ & $1.41^{b}$ & $1.08^{b}$ & $1.19^{b}$ & 0.31 & 0.002 \\
\hline Ochratoxin A, $\mu \mathrm{g} / \mathrm{kg}$ & 3.52 & 3.53 & 3.37 & 3.20 & 0.10 & 0.702 \\
\hline Deoxynivalenol, mg/kg & $0.58^{a}$ & $0.25^{b}$ & $0.22^{b}$ & $0.18^{b}$ & 0.05 & 0.005 \\
\hline
\end{tabular}

CON, biosorption without adding fungi; SC, biosorption with adding S. cerevisiae; $A O$, biosorption with adding $A$. oryzae; $A N$, biosorption with adding $A$. niger; SEM, standard error of the mean. Means within a row with different superscripts are different at $P<0.05$. rate and residual copper concentration among different groups in the same day, treatments $\mathrm{AN}, \mathrm{AO}$, and SC were significantly higher than $\mathrm{CON}(P<0.05)$. Overall, except with $\mathrm{CON}$, residual copper concentration decreased continuously, while the biosorption rate increased from D0 to D29. Residual copper concentration for $\mathrm{AN}$ was the lowest on D15, D22, and D29, and copper biosorption rate was the highest, averaging $84.85 \%$. Biosorption rate with AO reached $81.12 \%$ and with SC it averaged $80 \%$.

\section{Bacterial and Fungal Sequencing OTUs and Alpha Diversities}

The Venn diagram revealed that the numbers of unique OTUs for the CON, SC, AO, and AN were 130, 244, 82, and 92 of bacteria, respectively, and the shared OTU number was 1,177 (Figure 2A). For fungi, the unique OTU numbers were 46, 144, 135, and 89, respectively, and included 101 of shared OTUs (Figure 2B). The number of bacterial OTUs obtained by sequencing was much higher than that of fungi. In addition, detected OTU coverage index was greater than $99.70 \%$ for each treatment (Table 2).

In terms of bacterial alpha diversity (Table 2), compared with CON, fungal treatments did not change OTU numbers. No differences were observed in the Chao1, ACE, Shannon, and Simpson indexes among the CON and fungal treatments $(P>0.05)$. However, for fungal alpha diversity, $\mathrm{AO}$ and $\mathrm{AN}$ treatments decreased OTU numbers, Chaol, ACE, Shannon, and Simpson indexes compared with CON and SC treatments $(P<0.05)$.

\section{Bacterial and Fungal Community Abundance at Different Levels}

Figure 3 underscores that the species of bacteria were different at the phylum and genus levels. The taxonomic analysis at the phylum level revealed that bacterial communities were predominantly Firmicutes, Bacteroidetes, Actinobacteria, and Proteobacteria (Figure 3A). At the genus level, the dominant groups were Unknown_Marinilabiliaceae, Proteiniphilum, Gelidibacter, and Fermentimonas of phylum Bacteroidetes; Erysipelothrix, Ercella, Tissierella, and Christensenellaceae R-7 of phylum Firmicutes; Corynebacterium and Leucobacter of phylum Actinobacteria; Curvibacter of the phylum Proteobacteria; and Treponema of the phylum Spirochaetes (Figure 3B). A heatmap correlation analysis was established based on significant correlations among different bacteria for the top 10 genera (Figure 3C). The high abundance of Unknown_Marinilabiliaceae exhibited co-occurrence correlations with Proteiniphilum $(R=0.65)$ and Treponema $(R=0.89)$, Erysipelothrix exhibited co-occurrence correlations with Corynebacterium $(R=0.90)$, and Proteiniphilum exhibited co-occurrence correlations with Fermentimonas $(R=0.95)$, whereas it showed a negative interaction between Gelidibacter and Ercella $(R=-0.65)$.

The relative abundance of fungal communities among the four groups was examined at phylum, class, and genus levels, and the taxonomy of different levels varied among the four groups (Figure 4). Ascomycota, Mortierellomycota, and Basidiomycota mainly dominated the fungal communities 

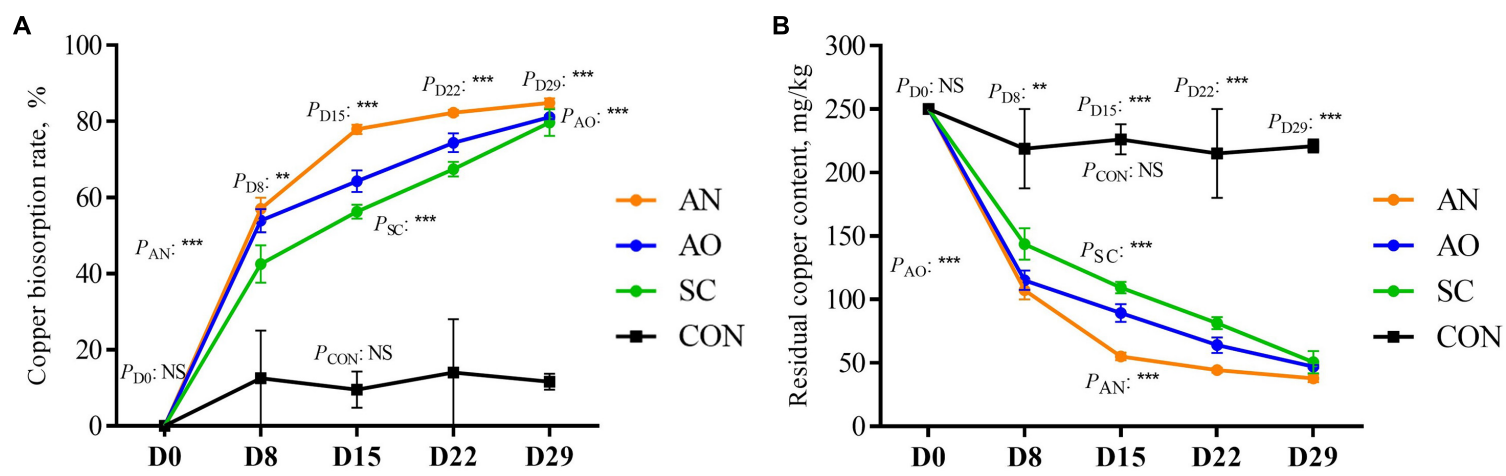

FIGURE 1 | Residual copper concentration and biosorption rate of copper in swine manure on D8, D15, D22, and D29. (A) Curve diagram of residual copper content in swine manure in different treatments over different days. (B) Curve diagram of copper biosorption rate of swine manure in different treatments over different days. CON, biosorption without adding fungi; SC, biosorption with adding S. cerevisiae; AO, biosorption with adding A. oryzae; AN, biosorption with adding A. niger. ${ }^{\star \star} P<0.01 ;{ }^{\star \star \star} P<0.001 ;{ }^{N S} P>0.05$.
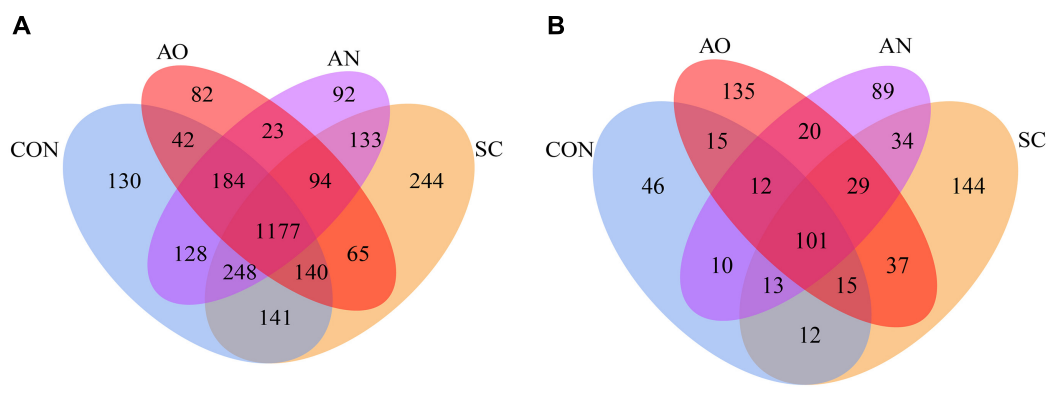

FIGURE 2 | Venn diagram of manure bacterial and fungal operational taxonomic units (OTUs). The number of unique OTUs was represented by the unoverlapped portion of Venn diagram for each group. (A) Bacterial Venn diagram and (B) fungal Venn diagram.

at the phylum level (Figure 4A). The relative abundances of Ascomycota in AO and AN were 98.08 and $95.87 \%$, respectively. At the class level, the dominant groups mainly included Sordariomycetes, Eurotiomycetes, Unknown_Ascomycota, Dothideomycetes, and Leotiomycetes of the phylum Ascomycota; Mortierellomycetes of the phylum Mortierellomycota; and Agaricomycetes of the phylum Basidiomycota (Figure 4B). Furthermore, at the genus level, the class Eurotiomycetes was represented by Aspergillus; the class Sordariomycetes was represented by Unknown_Sordariomycetes, Trichoderma, Unknown_Microascaceae, and Unknown_Hypocreales; and the class Mortierellomycetes was represented by Mortierella and Unknown_Mortierellales (Figure 4C). The heatmap correlation analysis of the top 10 fungal genera showed that the high abundance of Aspergillus had negative interactions with other fungal genera, while other genera mainly presented co-occurrence correlations among each other, which explained why Aspergillus present abundantly. Saccharomycetes only accounted for less than $0.05 \%$ of each group.

\section{Taxonomic Differences in Microbial Genus Level With AO and AN}

Significant taxonomic differences in bacterial and fungal genus classification between $\mathrm{CON}, \mathrm{AO}$, and $\mathrm{AN}$ groups were analyzed using LEfSe (Figure 5). LEfSe results were visualized using taxonomy bar chart. At the bacterial genus level between CON and AO (Figure 5A), Romboutsia, Clostridium sensu stricto 1, Turicibacter, and Agromyces were enriched in CON, whereas Bacteroides, Solibacillus, Streptococcus, and Trueperella were enriched in AN. Between CON and AN (Figure 5B), Romboutsia, Turicibacter, Hyphomicrobium, etc., were enriched in CON, whereas Aeromicrobium, Nitratireductor, and Flaviflexus were enriched in AN. At the fungal genus level between $\mathrm{CON}$ and AO (Figure 5C), Trichoderma, Mortierella, and Coprinopsis were enriched in CON, whereas Aspergillus was enriched in AO. Between CON and AN (Figure 5D), Trichoderma, Mortierella, and Chaetomium were enriched in CON, whereas Aspergillus was enriched in AN. The relative abundances of Aspergillus in AO and AN was 91.69 and 67.24\%, respectively (Figure 5E), which were significantly higher than those of CON $(2.20 \%)(P<0.01)$, but no significant difference was found between $\mathrm{AO}$ and $\mathrm{AN}(P>0.05)$.

\section{Co-occurrence of Bacteria and Fungi in the Copper Biosorption System}

The alpha diversity indexes and top 10 genera were used to determine correlations between bacteria and fungi. Figures 6AD underscore that both species richness (Chaol and ACE indexes) and species diversity (Shannon and Simpson indexes) 
TABLE 2 | Numbers of observed species, richness, and alpha diversity indices in biosorption samples from each treatments groups.

\begin{tabular}{|c|c|c|c|c|c|c|}
\hline \multirow[t]{2}{*}{ Items } & \multicolumn{4}{|c|}{ Treatments } & \multirow[t]{2}{*}{ SEM } & \multirow[t]{2}{*}{$P$-value } \\
\hline & CON & sc & AO & AN & & \\
\hline \multicolumn{7}{|l|}{ Bacteria } \\
\hline OTUs & $1,859.00$ & $2,076.67$ & $2,103.67$ & $1,821.33$ & 60.49 & 0.230 \\
\hline Chao1 index & $2,087.10$ & $2,273.60$ & $2,333.80$ & $2,097.70$ & 47.69 & 0.152 \\
\hline ACE index & $2,075.80$ & $2,285.60$ & $2,337.50$ & $2,123.60$ & 45.79 & 0.108 \\
\hline Shannon index & 6.41 & 7.37 & 7.39 & 6.81 & 0.16 & 0.064 \\
\hline Simpson index & 0.95 & 0.98 & 0.98 & 0.96 & 0.00 & 0.137 \\
\hline Coverage (\%) & 99.74 & 99.76 & 99.73 & 99.71 & 0.02 & 0.871 \\
\hline \multicolumn{7}{|l|}{ Fungi } \\
\hline OTUs & $309.00^{\mathrm{a}}$ & $345.33^{a}$ & $216.00^{b}$ & $222.00^{b}$ & 19.91 & 0.010 \\
\hline Chao1 index & $333.79^{a}$ & $351.29^{a}$ & $220.36^{b}$ & $243.20^{b}$ & 18.73 & 0.002 \\
\hline ACE index & $319.13^{a}$ & $350.23^{a}$ & $221.44^{b}$ & $239.08^{b}$ & 17.74 & 0.002 \\
\hline Shannon index & $4.04^{a}$ & $4.71^{\mathrm{a}}$ & $0.60^{b}$ & $1.64^{b}$ & 0.53 & $<0.001$ \\
\hline Simpson index & $0.75^{a}$ & $0.85^{a}$ & $0.15^{\mathrm{c}}$ & $0.49^{b}$ & 0.09 & 0.001 \\
\hline Coverage (\%) & 99.85 & 99.99 & 99.97 & 99.97 & 0.03 & 0.185 \\
\hline
\end{tabular}

CON, biosorption without adding fungi; $S C$, biosorption with adding S. cerevisiae; $A O$, biosorption with adding $A$. oryzae; $A N$, biosorption with adding $A$. niger; SEM, standard error of the mean; OTUs, operational taxonomic units; ACE index, abundance-based coverage estimator. Means within a row with different superscripts are different at $P<0.05$.

were not significantly correlated $(P>0.05)$. In addition, the relative abundance of Tissierella was positively correlated with Arthrographis, Unknown_Pleosporales, Unknown_Hypocreales, and Trichoderma $(R>0.5, P<0.05)$ but was negatively correlated with Aspergillus $(R<-0.5, P<0.05)$; the relative abundance of Fermentimonas and Proteiniphilum was positively correlated with Arthrographis $(R>0.5, P<0.05)$; the relative abundance of Corynebacterium and Erysipelothrix was positively correlated with Coprinopsis $(R>0.5, P<0.05)$ (Figure 6E).

\section{Prediction of Bacterial Functions via FAPROTAX or PICRUSt2}

The bacterial community ecological functions were investigated via FAPROTAX (Figure 7A). The results indicated that the bacterial community contained a high number of sequences assigned to chemoheterotrophy, aerobic chemoheterotrophy, and fermentation. Other ecological functions such as cellulolysis, animal parasites or symbionts, human pathogens, and all aromatic compound degradation were also predicted to be present among bacterial communities in relatively lower abundance. However, nearly $60 \%$ of the sequencing annotations could not be classified by FAPROTAX.

The bacterial functional predictions of KEGG pathways based on PICRUSt 2 are shown in Figures 7B,C. The results showed that the genes identified are potentially related to metabolism, genetic information processing, and environmental information processing with other pathways, including cellular processes, organismal systems, and human diseases presented in relatively lower abundance (Figure 7B). Based on metabolic pathways, most of the predicted genes are involved in carbohydrate metabolism, amino acid metabolism, energy

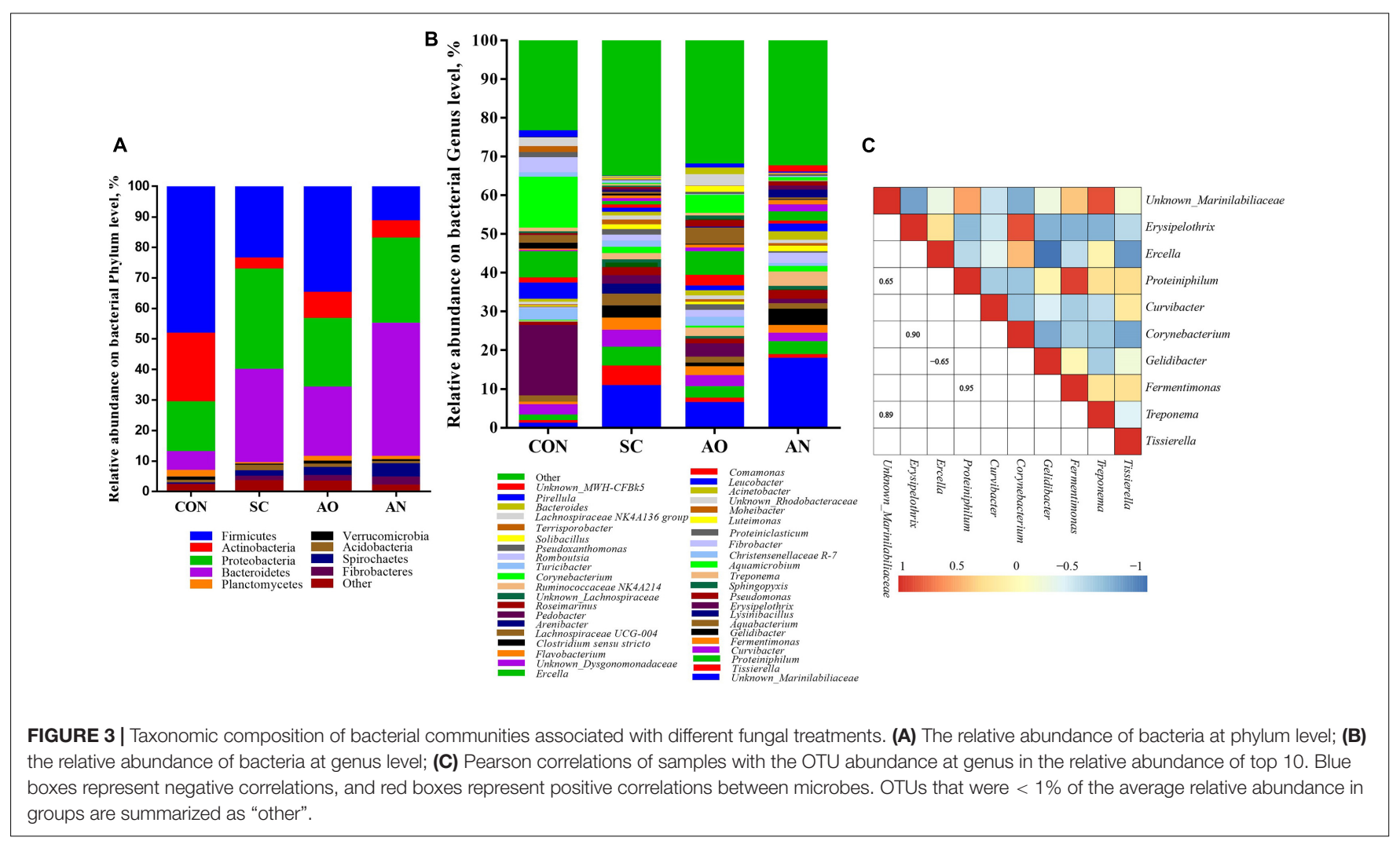




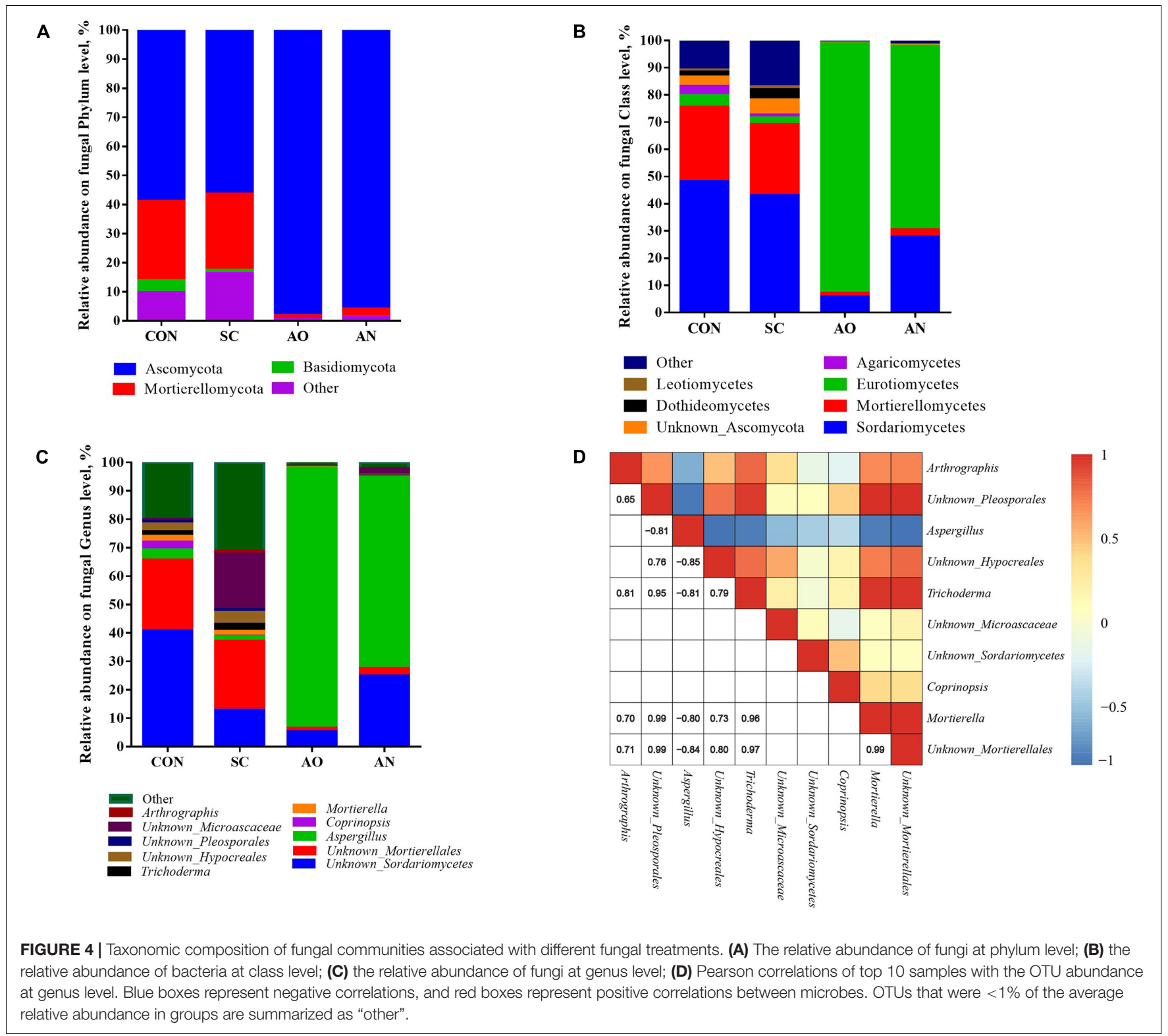

metabolism, nucleotide metabolism, and metabolism of cofactors and vitamins (Figure 7C). In addition, another pathway related to this study with a high abundance and environmental information processing had genes predicted to encode membrane transporters and signal transduction proteins (Figure 7C).

\section{DISCUSSION}

Detection of mycotoxins such as aflatoxin, ochratoxin, and deoxynivalenol is important to evaluate the biosafety of manure after biosorption of copper (Table 1). Aflatoxin is a metabolite produced by Aspergillus flavus, Aspergillus parasiticus, and other fungi, mainly including AFB1, AFB2, AFG1, and AFG2, among which AFB1 is the most toxic and harmful (Das et al., 2014). After crops are contaminated by AFB1 and consumed by animals, the toxins will be transmitted along with the food chain and eventually threaten the safety of human beings. Similarly, in the process of adding fungi to adsorb copper, if some fungi in manure produce AFB1, it will inevitably cause mycotoxin accumulation pollution after the production of organic fertilizer. The AFB1 of CON was significantly higher than that of SC, AO, and $\mathrm{AN}$, and this is because the Aspergillus added in manure detoxified the AFB1, for example, bacteria such as Bacillus licheniformis (Rao et al., 2017) and Pseudomonas aeruginosa (Samuel et al., 2014) and fungi such as A. niger (Xu et al., 2013) and Zygosaccharomyces rouxii (Zhou et al., 2017) can degrade $80-90 \%$ of AFB1. In addition, ochratoxin is another kind of mycotoxin found after aflatoxin. It is the metabolite of Aspergillus and Penicillium, such as Aspergillus ochre, A. niger, and Penicillium viridicatum (Puntaric et al., 2001). Among three types of ochratoxin (OTA, OTB, and OTC), OTA is the 


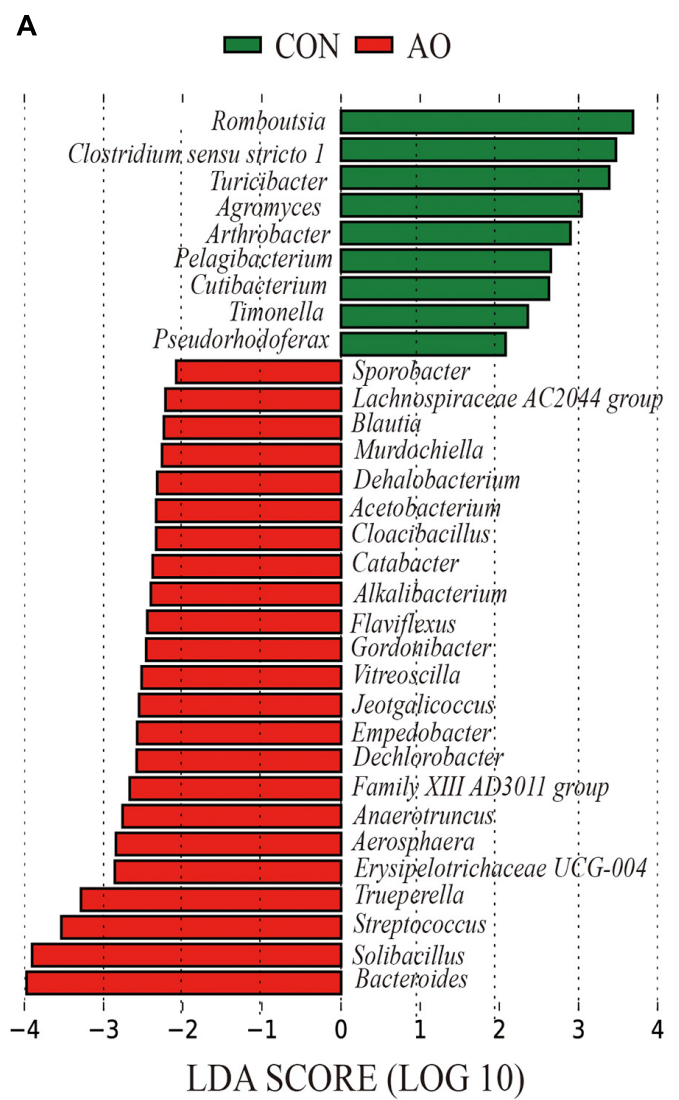

B

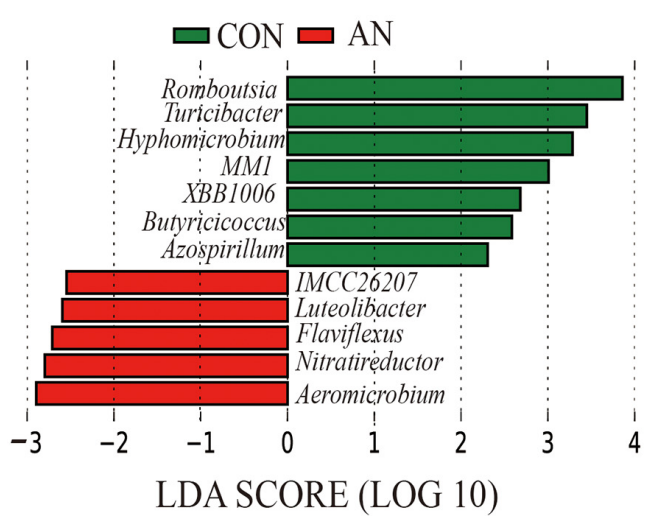

C

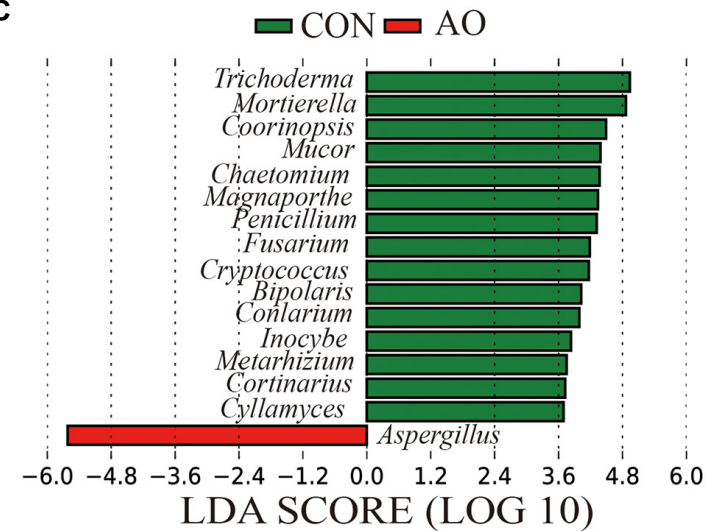

D $\square \mathrm{CON} \square \mathrm{AN}$

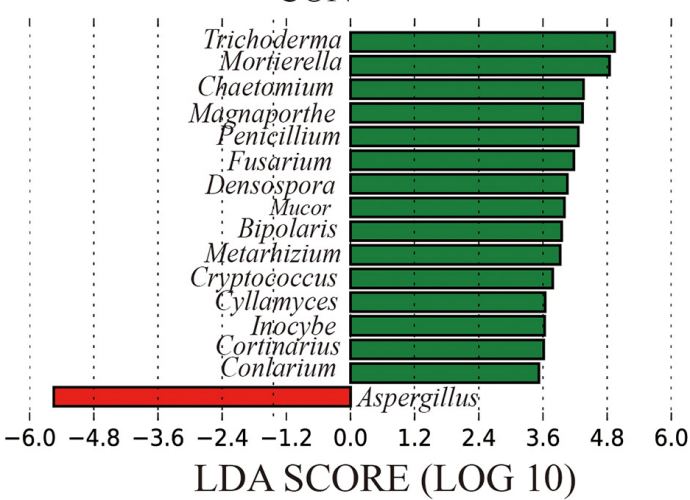

E

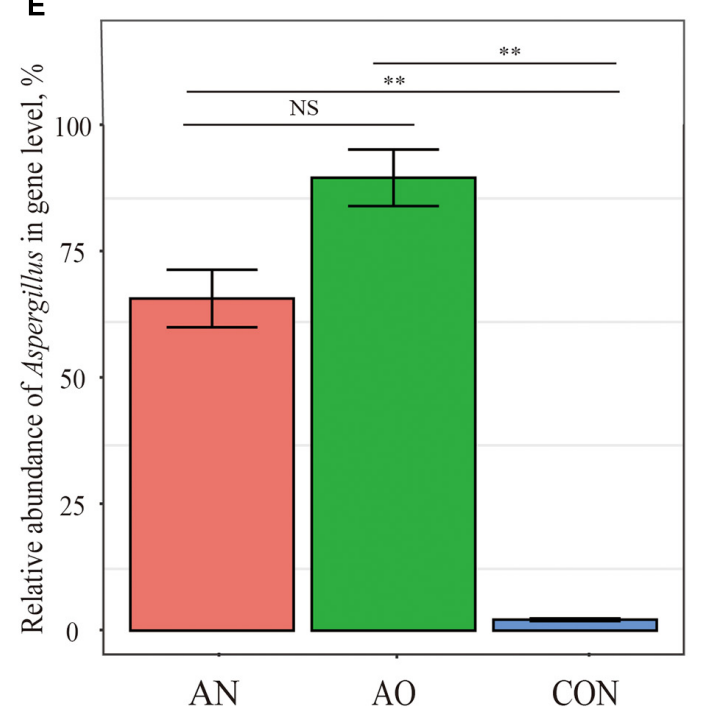

FIGURE 5 | Screening of significant taxonomic differences in microbial genus level of AO and AN using LEfSe. (A) Linear discriminant analysis (LDA) plus effect size (LEfSe) at bacterial genus levels of CON and AO; (B) LEfSe at bacterial genus levels of CON and AN; (C) LEfSe at fungal genus levels of CON and AO; (D) LEfSe at fungal genus levels of CON and AN. The LDA score that was higher in the CON is shown in green, whereas one LDA score that was elevated fungal treatments is depicted in red. Only LDA scores $>2$ were listed. (E) Comparative histogram of relative abundance of Aspergillus in AN, AO, and CON. ${ }^{\star \star} P<0.01,{ }^{N S} P>0.05$.

most toxic (Galtier et al., 1981). The concentrations of OTA were lower than $4.0 \mu \mathrm{g} / \mathrm{kg}$ among fungal treatments and $\mathrm{CON}$, suggesting that it is not produced in the biosorption process. Deoxynivalenol is another mycotoxin mainly produced by the metabolism of Fusarium that, at low doses, can lead to anorexia, vomiting, diarrhea, and fever in animals, and it is also harmful to the immune system (Pinton et al., 2010). The deoxynivalenol concentration of fungal treatments was below $0.25 \mathrm{mg} / \mathrm{kg}$, which 

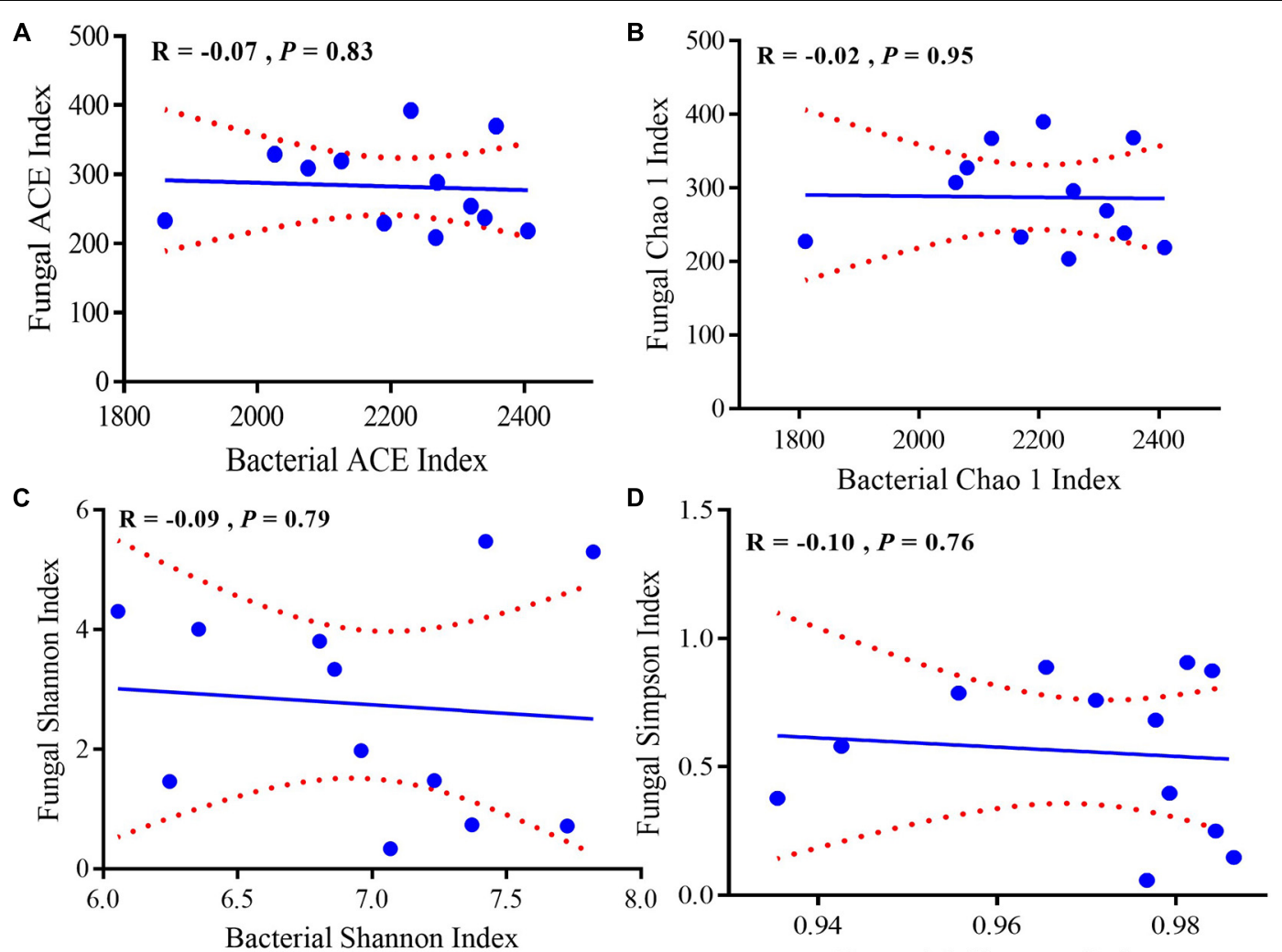

Bacterial Simpson Index

E

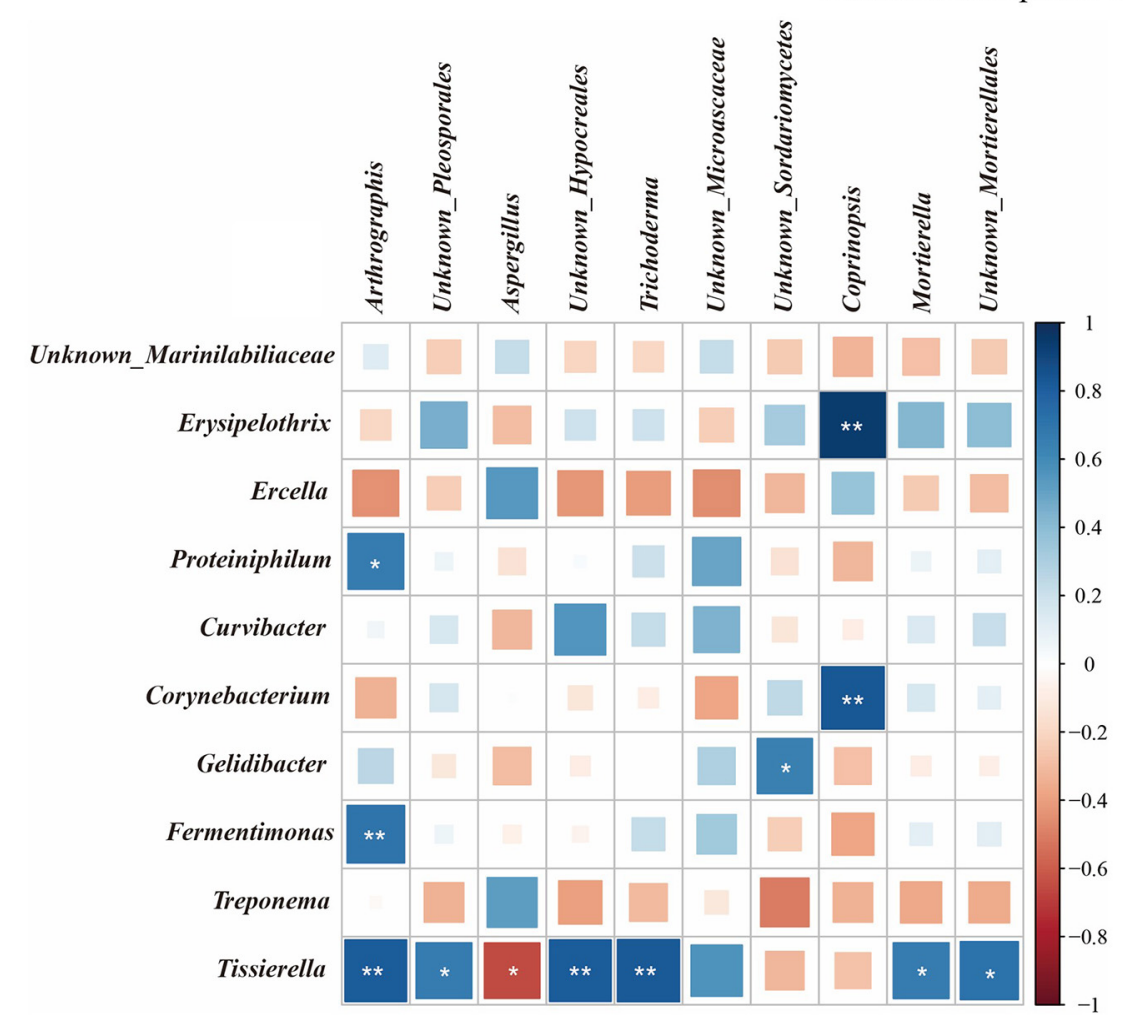

FIGURE 6 | Correlation of bacterial and fungal alpha diversity. (A) ACE, (B) Chao1, (C) Shannon, and (D) Simpson indexes. The Pearson correlation coefficient (R) and the significance level $(P)$ were shown on the plots. (E) Pearson correlations of samples with the OTU abundance of top 10 bacterial and fungal genera. Positive correlations are displayed in blue and negative correlations are shown in red. Color intensity and the size of the squares are proportional to the correlation coefficients. ${ }^{*}$ Means significant correlations with $|R|>0.5$ and $P<0.05$ while ${ }^{* *}$ Means significant correlations with $|R|>0.5$ and $P<0.01$. 


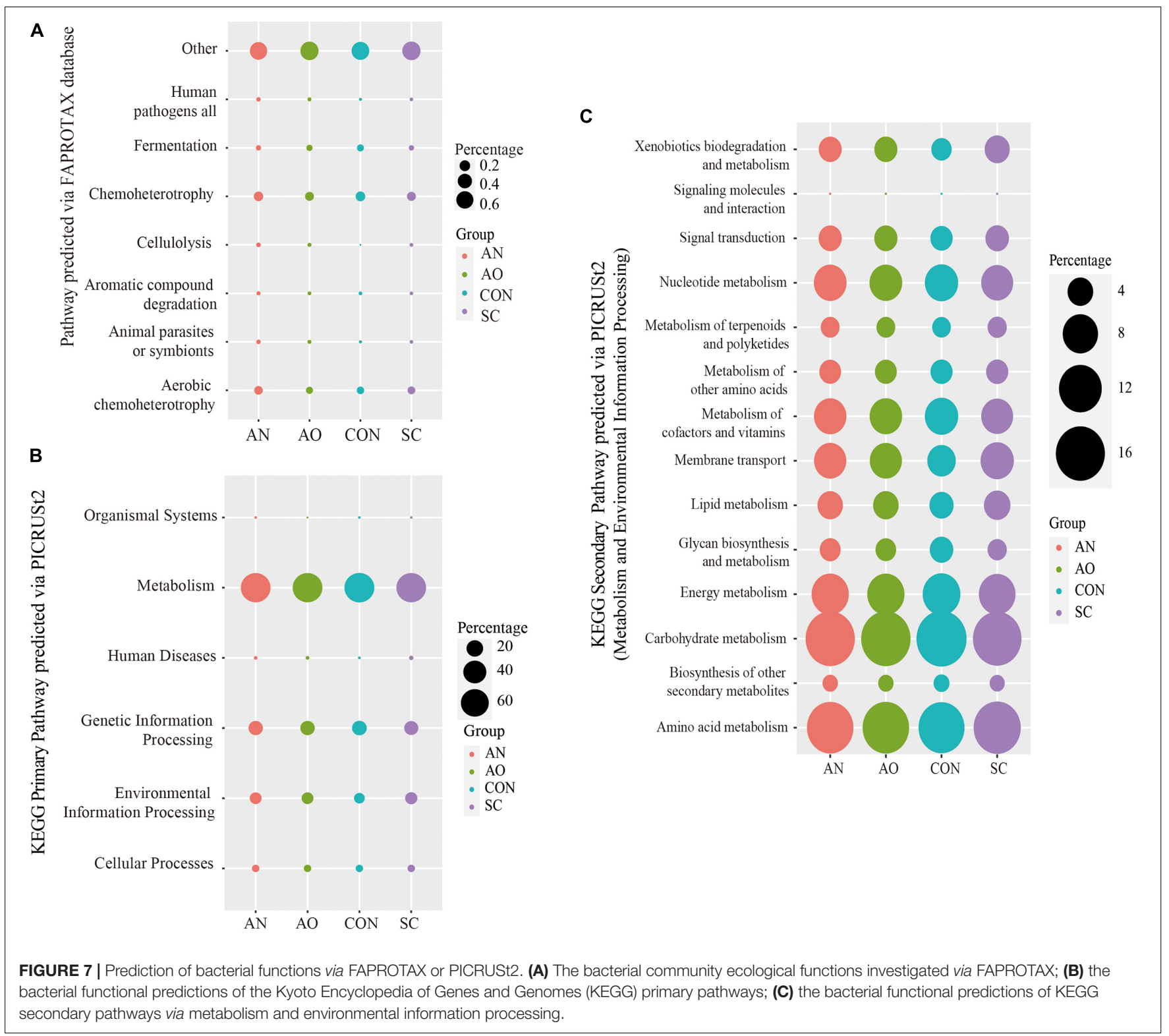

was significantly lower than CON. It is possible that $S$. cerevisiae (Repeckiene et al., 2013), A. oryzae (Garda-Buffon et al., 2011), or some anaerobic bacteria and bacillus degraded deoxynivalenol. Overall, the concentration of mycotoxins in swine manure going through fermentation was extremely low, suggesting it is safe for production of bio-organic fertilizer or bedding.

The low production cost, high adsorption efficiency, and wide range of usage render biosorption of heavy metals using bacteria and fungi one of the most common methods to reduce pollution in manure (Solisio et al., 2006; Lodi et al., 2008). The most effective approach in the present experiment was $A$. niger, $0.4 \%$ addition with a copper concentration of $250 \mathrm{mg} / \mathrm{kg}$ and a biosorption rate of $84.85 \%$. A. oryzae also had an adsorption rate of over $80 \%$, which was due to the characteristics of Aspergillus themselves (Figure 1). Price et al. (2001) found that A. niger is capable of removing $91 \%$ of copper and $70 \%$ of zinc from swine wastewater. Proteomic analysis of A. niger showed that its capacity to absorb metals was boosted by physiological modification under stress, more specifically antioxidant responses induced by activity of catalase, superoxide dismutase, and cytochrome c peroxidase (Dias et al., 2019). Luna et al. (2015) found that exposing A. niger cells to increasingly large concentrations of copper led to ultrastructural changes in the cell surface, electron density, thickness, and septation. In addition, this strain has strong adaptability to the environment, a wide range of culture substrate sources, and the spores, and aerial hyphae produced also have biosorption capacity (Wang and Cui, 2017). Amounts of fungi as low as $0.4 \%$ were effective to elicit a strong biosorption effect; thus, only small amounts of these microorganisms would be needed in practice. One reason for this strong effect is that the biosorption capacity of metals increases rapidly at the beginning, and after reaching the equilibrium point, 
the biosorption capacity decreases with addition of the strain (Sag and Kutsal, 2000). Thus, if more strain was added above the $0.4 \%$ used in the present study, it might have led to a decrease in biosorption rate. When using $A$. niger to adsorb copper, Mukhopadhyay et al. (2007) found that the amount of metal ions adsorbed by fungi per gram decreased with the increase of strain biomass. Increased biomass interfered with the binding sites between metal ions and the strain. The adsorbed metal ions block the voids on the cell surface or agglomerate between ions, leading to reduced availability of active sites. The enrichment of high biomass will form a shielding effect in the outer layer, thus reducing the biosorption of metal ions.

The temperature was between 18.47 and $18.77^{\circ} \mathrm{C}$, while $\mathrm{pH}$ was between 6.33 and 6.91 in the biosorption system and was close to the neutral $\mathrm{pH}$ and indoor temperature (Table 1). It has been reported that $\mathrm{pH}$ also affects the biosorption efficiency. A slightly acidic $\mathrm{pH}$ is more suitable for fungi to absorb heavy metals; under this acidic environment, fungi have the highest biological activity, the best quality of mycelium and spores, and the strongest negative charge on the surface of fungal cells, which are more conducive to the positive ions (Sepehr et al., 2012). Kapoor and Viraraghavan (1997) adsorbed lead ion, nickel ion, and cobalt ion with $A$. niger, and the results showed that, to a certain extent, the higher the $\mathrm{pH}$ value, the higher the biosorption rate, and no biosorption was observed when the $\mathrm{pH}$ was 3.0. The biosorption capacity was at maximum when the $\mathrm{pH}$ increased between 4 and 6 , as the $\mathrm{pH}$ affected the metabolic activity of the fungi. The $\mathrm{pH}$ between 5 and 5.5 is favorable for sorption of pollutants especially heavy metals by Aspergillus sp., whereas $S$. cerevisiae shows tolerance and adaptation at $\mathrm{pH} 2.5-4.5$. One of the possible reasons for the low relative abundance of $S$. cerevisiae in this experiment may be that the $\mathrm{pH}$ was not suitable for its growth. Thus, optimal conditions of $\mathrm{pH}$ should be considered when using fungi to develop high copper adsorbents. In addition, in the manure composting industry, A. niger can also turn macromolecules into small molecules and decompose insoluble substances into easy-to-volume substances. The physical and chemical properties of fertilizer have been greatly improved in the process of composting, thus increasing the economic benefit of the fertilizer and leading to higher forage yield ( $\mathrm{Du}$ et al., 2020). Clearly, using A. niger can not only effectively remove copper in feces but also improve the commercial value of manure as organic fertilizer, underscoring the potential for practical application of this strain.

For alpha diversity of bacteria, there were no significant differences between Chao1, ACE, Shannon, and Simpson indexes $(P>0.05)$, suggesting that the species richness and diversity in the bacterial community were consistent among the four groups. Fungal treatment had no effect on bacterial community (Table 2). In contrast, compared with the CON and S. cerevisiae treatments, $A$. oryzae and $A$. niger treatments decreased the OTU numbers and Chao1, ACE, Shannon, and Simpson indexes $(P<0.05)$ (Table 2). This suggested that fungal treatments reduced the diversity and richness of fungal population, but had no effect on bacterial population. A. oryzae and A. niger addition significantly increased the proportion of Aspergillus. The proportion of $S$. cerevisiae was observed abnormally lower to be the dominant fungi for biosorption (accounted for $<0.05 \%$ ). Compared with CON, the addition of $S$. cerevisiae did not change the fungal community, but after addition of $A$. niger and $A$. oryzae, these two fungi grew and propagated rapidly, which inhibited the activity of other bacteria and fungi such as Tissierella, Unknown_Hypocreales, Trichoderma, and Mortierella (Figures 4D, 6E). This effect caused a reduction of the richness and diversity of species. The specific reasons for the failure of $S$. cerevisiae to grow need further analysis. It is possible that some antibiotics, traditional Chinese medicine preparations, and antifungal agents in swine manure inhibited its growth including phenolic and phenolic acids (Adeboye et al., 2014). In addition, some other fungi competed to inhibit S. cerevisiae growth or the biosorption environment was not suitable to support active growth of S. cerevisiae.

Bacteroides, Solibacillus, Streptococcus, Aeromicrobium, Nitratireductor, and Nitratireductor were the dominant bacteria in the Aspergillus treatments; fungal dominant species only contained Aspergillus (Figure 5). These bacteria genera mainly belong to Bacteroidetes, Firmicutes, and Proteobacteria phyla. They are the dominant phyla taxonomy in the gastrointestinal tract and manure of swine (Yang et al., 2016). Bacteroidetes and Firmicutes phyla are mainly related to carbohydrate metabolism, while Proteobacteria phyla are mostly related to protein metabolism (Lamendella et al., 2011; Regmi et al., 2011). This is consistent with our findings on the prediction of bacterial pathways (Figure 7). Results of bacterial community ecological function analysis via FAPROTAX indicated that bacteria were mainly associated with chemoheterotrophy, aerobic chemoheterotrophy, and fermentation. In addition, the bacterial functional predictions of KEGG pathways based on PICRUSt2 showed that genes were potentially related to carbohydrate metabolism, amino acid metabolism, energy metabolism, and nucleotide metabolism. The leading role of bacteria in the adsorption process is to decompose fecal organic matter, where the metabolism produces various kinds of nutrients. The dominant bacteria have strong degradation ability and mainly play a role in accelerating manure decay, decomposing toxic substances, and shortening the time of making organic fertilizers. It is noteworthy that some bacteria also have an ability to adsorb metal ions. The extracellular polysaccharides produced by Lactococcus lactis of Firmicutes phylum, Methylobacterium organophilum of Proteobacteria phylum, and Anabaena spiroides of Cyanobacteria phylum are an essential component of copper tolerance and biosorption (Gupta and Diwan, 2017; Kou et al., 2018). In addition, Nostoc punctiforme and Cyanobacterium Synechococcus of Cyanobacteria and Pseudomonas putida of Proteobacteria phylum can also produce metallothioneins to protect against metal toxicity (Hudek et al., 2009; Gupta and Diwan, 2017). Kou et al. (2018) concluded that Methylobacillus, Solirubrobacter, Ohtaekwangia, Polaromonas vacuolata, Yonghaparkia alkaliphila, and Nitrosospira are adapted to high metal concentrations and thus can be used readily in metal-treated soils. The biosorption rate of $S$. cerevisiae reached $77.92 \%$, which might be due to the reason that Trichoderma of Sordariomycetes absorbed a portion of the added copper. Trichoderma also 
have strong biosorption of copper and have been widely used in practice. Furthermore, Trichoderma can also produce antibacterial proteins, which can not only kill pathogens in soil or feces through certain biosorption carriers but also improve nutrient utilization efficiency and repair agrochemicalpolluted environments (Schuster and Schmoll, 2010). The above dominant microorganisms work together, where bacteria promote manure fermentation and fungi absorb copper and reduce copper pollution, both of which are of high practical value in production settings.

\section{CONCLUSION}

In conclusion, $A$. niger and $A$. oryzae at a concentration of $0.4 \%$ and $250 \mathrm{mg} / \mathrm{kg}$ copper resulted in the greatest average copper biosorption rate, $\sim 85 \%$. Both strains had a remarkable effect on reducing copper, and further optimization of parameters along with the use of embedding materials can lead to the development of an adsorbent for practical application. Although fungal treatments reduced the diversity and richness of fungal abundance, they had no effect on bacterial abundance. Overall, there may be multiple mechanisms acting synergistically to biotransform and adsorb copper so as to maintain a relatively stable state of copper ions in fungal cells. More studies are needed to better understand the specific pathways of copper biosorption by fungi such as Aspergillus.

\section{REFERENCES}

Adeboye, P. T., Bettiga, M., and Olsson, L. (2014). The chemical nature of phenolic compounds determines their toxicity and induces distinct physiological responses in Saccharomyces cerevisiae in lignocellulose hydrolysates. AMB Express 4:46.

Apgar, G. A., Kornegay, E. T., Lindemann, M. D., and Notter, D. R. (1995). Evaluation of copper sulfate and a copper lysine complex as growth promoters for weanling swine. J. Anim. Sci. 73:2640. doi: 10.2527/1995.7392640x

Armstrong, T. A., Spears, J. W., van Heugten, E., Engle, T. E., and Wright, C. L. (2000). Effect of copper source (cupric citrate vs cupric sulfate) and level on growth performance and copper metabolism in pigs. Asian Australas J. Anim. Sci. 13, 1154-1161. doi: 10.5713/ajas.2000.1154

Arnesano, F., Banci, L., Bertini, I., Cantini, F., Ciofi-Baffoni, S., Huffman, D. L., et al. (2001). Characterization of the binding interface between the copper chaperone Atx1 and the first cytosolic domain of Ccc2 ATPase. J. Biol. Chem. 276, 41365-41376. doi: 10.1074/jbc.M104807200

Bai, L. Y., Zeng, X. B., Su, S. M., Duan, R., Wang, Y. N., and Gao, X. (2015). Heavy metal accumulation and source analysis in greenhouse soils of Wuwei District, Gansu Province, China. Environ. Sci. Pollut. Res. Int. 22, 5359-5369. doi: 10.1007/s11356-014-3763-1

Caporaso, J. G., Bittinger, K., Bushman, F. D., DeSantis, T. Z., Andersen, G. L., and Knight, R. (2010). PyNAST: a flexible tool for aligning sequences to a template alignment. Bioinformatics 26, 266-267. doi: 10.1093/bioinformatics/btp636

Chang, J. S., Law, R., and Chang, C. C. (1997). Biosorption of lead, copper and cadmium by biomass of Pseudomonas aeruginosa PU21. Water Res. 31, 1651-1658. doi: 10.1016/S0043-1354(97)00008-0

Chen, H., and Boutros, P. C. (2011). VennDiagram: a package for the generation of highly-customizable Venn and Euler diagrams in R. BMC Bioinformatics 12:35. doi: 10.1186/1471-2105-12-35

Cui, H. B., Fan, Y. C., Fang, G. D., Zhang, H. X., Su, B. B., and Zhou, J. (2016). Leachability, availability and bioaccessibility of $\mathrm{Cu}$ and $\mathrm{Cd}$ in a contaminated soil treated with apatite, lime and charcoal: a five-year field experiment. Ecotoxicol. Environ. Saf. 134, 148-155. doi: 10.1016/j.ecoenv.2016.07.005

\section{DATA AVAILABILITY STATEMENT}

The datasets presented in this study can be found in online repositories. The names of the repository/repositories and accession number(s) can be found below: https://www.ncbi.nlm. nih.gov/, BioProject PRJNA704785.

\section{AUTHOR CONTRIBUTIONS}

MW, YZ, YuG, KS, and JL designed the experiments and revised the manuscript. YZ, YaG, and XY conducted the experiments. MW, YuG, PL, and JX offered the experimental reagents and materials. YZ analyzed the data and finished the manuscript. YZ, MW, KS, and JL prepared the figures and edited the manuscript. All authors reviewed the manuscript.

\section{FUNDING}

This work was supported by the National 13th Five-Year Plan Key Research and Development Program (2017YFD0800200 and 2018YFD0502100), Jiangxi Key Research and Development Program (20201BBF61008), Environmental Control Innovation Team of Jiangsu Modern Agriculture (Pig) Industrial Technology System [JATS(2020)323], and Priority Academic Program Development of Jiangsu Higher Education Institutions, China.

Dancis, A., Yuan, D., Haile, D., Askwith, C., Eide, D., Moehle, C., et al. (1994). Molecular characterization of a copper transport protein in S. cerevisiae. Cell 76, 393-402. doi: 10.1016/0092-8674(94)90345-X

Das, A., Bhattacharya, S., Palaniswamy, M., and Angayarkanni, J. (2014). Biodegradation of aflatoxin $\mathrm{B} 1$ in contaminated rice straw by Pleurotus ostreatus MTCC 142 and Pleurotus ostreatus GHBBF10 in the presence of metal salts and surfactants. World J. Microbiol. Biotechnol. 30, 2315-2324. doi: 10.1007/s11274-014-1657-5

Dias, M., de Lacerda, J. T. J. G., de Almeida, S. P. C., de Andrade, L. M., do Nascimento, C. A. O., Rozas, E. E., et al. (2019). Response mechanism of mineisolated fungus Aspergillus niger IOC 4687 to copper stress determined by proteomics. Metallomics 11, 1558-1566. doi: 10.1039/c9mt00137a

Du, X. R., Li, B., Chen, K. J., Zhao, C., Xu, L. J., Yang, Z. D., et al. (2020). Rice straw addition and biological inoculation promote the maturation of aerobic compost of rice straw biogas residue. Biomass. Conv. Bioref. 10, 1-10. doi: 10.1007/s13399-019-00587-y

Dursun, A. Y. (2006). A comparative study on determination of the equilibrium, kinetic and thermodynamic parameters of biosorption of copper(II) and lead(II) ions onto pretreated Aspergillus niger. Biochem. Eng. J. 28, 187-195. doi: 10.1016/j.bej.2005.11.003

Edgar, R. C. (2013). UPARSE: highly accurate OTU sequences from microbial amplicon reads. Nat. Methods 10, 996-998. doi: 10.1038/Nmeth.2604

Eneji, A. E., Yamamoto, S., Honna, T., and Ishiguro, A. (2001). Physico-chemical, changes in livestock feces during composting. Commun. Soil Sci. Plant Anal. 32, 477-489. doi: 10.1081/Css-100103023

Essel, E., Xie, J. H., Deng, C. C., Peng, Z. K., Wang, J. B., Shen, J. C., et al. (2019). Bacterial and fungal diversity in rhizosphere and bulk soil under different long-term tillage and cereal/legume rotation. Soil Tillage Res. 194:104302. doi: 10.1016/j.still.2019.104302

Ewing, H. P., Pesti, G. M., Bakalli, R. I., and Menten, J. F. (1998). Studies on the feeding of cupric sulfate pentahydrate, cupric citrate, and copper oxychloride to broiler chickens. Poult. Sci. 77, 445-448. doi: 10.1093/ps/77.3.445

Galtier, P., Alvinerie, M., and Charpenteau, J. L. (1981). The pharmacokinetic profiles of ochratoxin A in pigs, rabbits and chickens. 
Food Cosmet. Toxicol. 19, 735-738. doi: 10.1016/0015-6264(81)9 0528-9

Garda-Buffon, J., Kupski, L., and Badiale-Furlong, E. (2011). Deoxynivalenol (DON) degradation and peroxidase enzyme activity in submerged fermentation. Ciencia E Tecnologia De Alimentos 31, 198-203. doi: 10.1590/S0101-20612011000100030

Georgatsou, E., Mavrogiannis, L., Fragiadakis, G., and Alexandraki, D. (1997). The yeast Fre1p/Fre2p cupric reductases facilitate copper uptake and are regulated by the copper-modulated Maclp activator. J. Biol. Chem. 272, 13786-13792. doi: $10.1074 /$ jbc. 272.21 .13786

Gunasundari, E., and Kumar, P. S. (2017). Adsorption isotherm, kinetics and thermodynamic analysis of $\mathrm{Cu}(\mathrm{II})$ ions onto the dried algal biomass (Spirulina platensis). J. Ind. Eng. Chem. 56, 129-144. doi: 10.1016/j.jiec.2017.07.005

Gupta, P., and Diwan, B. (2017). Bacterial exopolysaccharide mediated heavy metal removal: a review on biosynthesis, mechanism and remediation strategies. Biotechnol. Rep. (Amst) 13, 58-71. doi: 10.1016/j.btre.2016.12.006

Hale, B., Evans, L., and Lambert, R. (2012). Effects of cement or lime on Cd, Co, $\mathrm{Cu}, \mathrm{Ni}, \mathrm{Pb}, \mathrm{Sb}$ and $\mathrm{Zn}$ mobility in field-contaminated and aged soils. J. Hazard. Mater. 199-200, 119-127. doi: 10.1016/j.jhazmat.2011.10.065

Heaton, D., Nittis, T., Srinivasan, C., and Winge, D. R. (2000). Mutational analysis of the mitochondrial copper metallochaperone Cox17. J. Biol. Chem. 275, 37582-37587. doi: 10.1074/jbc.M006639200

Hudek, L., Rai, L. C., Freestone, D., Michalczyk, A., Gibson, M., Song, Y. F., et al. (2009). Bioinformatic and expression analyses of genes mediating zinc homeostasis in Nostoc punctiforme. Appl. Environ. Microbiol. 75, 784-791. doi: 10.1128/Aem.02481-08

Inouhe, M., Sumiyoshi, M., Tohoyama, H., and Joho, M. (1996). Resistance to cadmium ions and formation of a cadmium-binding complex in various wildtype yeasts. Plant Cell Physiol. 37, 341-346. doi: 10.1093/oxfordjournals.pcp. a028951

Javanbakht, V., Alavi, S. A., and Zilouei, H. (2014). Mechanisms of heavy metal removal using microorganisms as biosorbent. Water Sci. Technol. 69, 17751787. doi: $10.2166 /$ wst. 2013.718

Jondreville, C., Revy, P. S., and Dourmad, J. Y. (2003). Dietary means to better control the environmental impact of copper and zinc by pigs from weaning to slaughter. Livest. Prod. Sci. 84, 147-156. doi: 10.1016/j.livprodsci.2003.09.011

Jones, S., Bardos, R. P., Kidd, P. S., Mench, M., de Leij, F., Hutchings, T., et al. (2016). Biochar and compost amendments enhance copper immobilisation and support plant growth in contaminated soils. J. Environ. Manag. 171, 101-112. doi: 10.1016/j.jenvman.2016.01.024

Kapoor, A., and Viraraghavan, T. (1997). Heavy metal biosorption sites in Aspergillus niger. Bioresour. Technol. 61, 221-227. doi: 10.1016/S0960-8524(97) 00055-2

Kou, S., Vincent, G., Gonzalez, E., Pitre, F. E., Labrecque, M., and Brereton, N. J. B. (2018). The response of a $16 \mathrm{~S}$ ribosomal RNA gene fragment amplified community to lead, zinc, and copper pollution in a Shanghai field trial. Front. Microbiol. 9:366. doi: 10.3389/fmicb.2018.00366

Lamendella, R., Domingo, J. W. S., Ghosh, S., Martinson, J., and Oerther, D. B. (2011). Comparative fecal metagenomics unveils unique functional capacity of the swine gut. BMC Microbiol. 11:103. doi: 10.1186/1471-2180-11-103

Langille, M. G. I., Zaneveld, J., Caporaso, J. G., McDonald, D., Knights, D., Reyes, J. A., et al. (2013). Predictive functional profiling of microbial communities using 16S rRNA marker gene sequences. Nat. Biotechnol. 31:814. doi: 10.1038/ nbt. 2676

Li, J. L., Li, C. C., Wang, M., Wang, L. X., Liu, X. B., Gao, C. L., et al. (2021). Gut structure and microbial communities in Sirex noctilio (Hymenoptera: Siricidae) and their predicted contribution to larval nutrition. Front. Microbiol. 12:641141. doi: $10.3389 /$ fmicb.2021.641141

Liti, G., Carter, D. M., Moses, A. M., Warringer, J., Parts, L., James, S. A., et al. (2009). Population genomics of domestic and wild yeasts. Nature 458, 337-341. doi: $10.1038 /$ nature 07743

Lodi, A., Soletto, D., Solisio, C., and Converti, A. (2008). Chromium(III) removal by spirulina platensis biomass. Chem. Eng. J. 136, 151-155. doi: 10.1016/j.cej. 2007.03.032

Long, D. D., Wang, Q., and Han, J. R. (2017). Biosorption of copper (II) from aqueous solutions by sclerotiogenic Aspergillus oryzae G15. Water Environ. Res. 89, 703-713. doi: 10.2175/106143017x14839994523749
Louca, S., Parfrey, L. W., and Doebeli, M. (2016). Decoupling function and taxonomy in the global ocean microbiome. Science 353, 1272-1277. doi: 10. 1126/science.aaf4507

Luna, M. A. C., Vieira, E. R., Okada, K., Campos-Takaki, G. M., and do Nascimento, A. E. (2015). Copper-induced adaptation, oxidative stress and its tolerance in Aspergillus niger UCP1261. Electron. J. Biotech. 18, 418-427. doi: 10.1016/j.ejbt. 2015.09.006

Luo, X. G., and Dove, C. R. (1996). Effect of dietary copper and fat on nutrient utilization, digestive enzyme activities, and tissue mineral levels in weanling pigs. J. Anim. Sci. 74, 1888-1896. doi: 10.2527/1996.7481888x

Magoc, T., and Salzberg, S. L. (2011). FLASH: fast length adjustment of short reads to improve genome assemblies. Bioinformatics 27, 2957-2963. doi: 10.1093/ bioinformatics/btr507

Meier, S., Curaqueo, G., Khan, N., Bolan, N., Rilling, J., Vidal, C., et al. (2017). Effects of biochar on copper immobilization and soil microbial communities in a metal-contaminated soil. J. Soils Sediments 17, 1237-1250. doi: 10.1007/ s11368-015-1224-1

Mukhopadhyay, M., Noronha, S. B., and Suraishkumar, G. K. (2007). Kinetic modeling for the biosorption of copper by pretreated Aspergillus niger biomass. Bioresour. Technol. 98, 1781-1787. doi: 10.1016/j.biortech.2006.06.025

Nicholson, F. A., Chambers, B. J., Williams, J. R., and Unwin, R. J. (1999). Heavy metal contents of livestock feeds and animal manures in England and Wales. Bioresour. Technol. 70, 23-31. doi: 10.1016/S0960-8524(99)0 0017-6

Nilsson, R. H., Larsson, K. H., Taylor, A. F. S., Bengtsson-Palme, J., Jeppesen, T. S., Schigel, D., et al. (2019). The UNITE database for molecular identification of fungi: handling dark taxa and parallel taxonomic classifications. Nucleic Acids Res. 47, D259-D264. doi: 10.1093/nar/gky1022

Noormohamadi, H. R., Fat'hi, M. R., Ghaedi, M., and Ghezelbash, G. R. (2019). Potentiality of white-rot fungi in biosorption of nickel and cadmium: modeling optimization and kinetics study. Chemosphere 216, 124-130. doi: 10.1016/j. chemosphere.2018.10.113

Nyantakyi, A. J., Akoto, O., and Fei-Baffoe, B. (2019). Seasonal variations in heavy metals in water and sediment samples from river Tano in the Bono, Bono East, and Ahafo Regions, Ghana. Environ. Monit. Assess. 191:570. doi: 10.1007/ s10661-019-7744-1

Osmanlioglu, A. E. (2018). Decontamination of radioactive wastewater by twostaged chemical precipitation. Nucl. Eng. Technol. 50, 886-889. doi: 10.1016/ j.net.2018.04.009

Park, J. H., Choppala, G. K., Bolan, N. S., Chung, J. W., and Chuasavathi, T. (2011). Biochar reduces the bioavailability and phytotoxicity of heavy metals. Plant Soil 348, 439-451. doi: 10.1007/s11104-011-0948-y

Pinton, P., Braicu, C., Nougayrede, J. P., Laffitte, J., Taranu, I., and Oswald, I. P. (2010). Deoxynivalenol impairs porcine intestinal barrier function and decreases the protein expression of claudin- 4 through a mitogen-activated protein kinase-dependent mechanism. J. Nutr. 140, 1956-1962. doi: 10.3945/ jn.110.123919

Price, M. S., Classen, J. J., and Payne, G. A. (2001). Aspergillus niger absorbs copper and zinc from swine wastewater. Bioresour. Technol. 77, 41-49. doi: 10.1016/S0960-8524(00)00135-8

Puntaric, D., Bosnir, J., Smit, Z., Skes, I., and Baklaic, Z. (2001). Ochratoxin A in corn and wheat: geographical association with endemic nephropathy. Croat. Med. J. 42, 175-180.

Quast, C., Pruesse, E., Yilmaz, P., Gerken, J., Schweer, T., Yarza, P., et al. (2013). The SILVA ribosomal RNA gene database project: improved data processing and web-based tools. Nucleic Acids Res. 41, D590-D596. doi: 10.1093/nar/gks1219

Rao, K. R., Vipin, A. V., Hariprasad, P., Appaiah, K. A. A., and Venkateswaran, G. (2017). Biological detoxification of aflatoxin B1 by Bacillus licheniformis CFR1. Food Control 71, 234-241. doi: 10.1016/j.foodcont.2016.06.040

Regmi, P. R., Metzler-Zebeli, B. U., Ganzle, M. G., van Kempen, T. A. T. G., and Zijlstra, R. T. (2011). Starch with high amylose content and low in vitro digestibility increases intestinal nutrient flow and microbial fermentation and selectively promotes bifidobacteria in pigs. J. Nutr. 141, 1273-1280. doi: 10. 3945/jn.111.140509

Repeckiene, J., Levinskaite, L., Paskevicius, A., and Raudoniene, V. (2013). Toxinproducing fungi on feed grains and application of yeasts for their detoxification. Pol. J. Vet. Sci. 16, 391-393. doi: 10.2478/pjvs-2013-0054 
Sag, Y., and Kutsal, T. (2000). Determination of the biosorption heats of heavy metal ions on Zoogloea ramigera and Rhizopus arrhizus. Biochem. Eng. J. 6, 145-151. doi: 10.1016/S1369-703x(00)00083-8

Samuel, M. S., Sivaramakrishna, A., and Mehta, A. (2014). Degradation and detoxification of aflatoxin B1 by Pseudomonas putida. Int. Biodeterior. Biodegradation 86, 202-209. doi: 10.1016/j.ibiod.2013.08.026

Sayer, J. A., and Gadd, G. M. (1997). Solubilization and transformation of insoluble inorganic metal compounds to insoluble metal oxalates by Aspergillus niger. Mycol. Res. 101, 653-661. doi: 10.1016/j.transproceed.2008.03.121

Schmidt, P. J., Rae, T. D., Pufahl, R. A., Hamma, T., Strain, J., O’Halloran, T. V., et al. (1999). Multiple protein domains contribute to the action of the copper chaperone for superoxide dismutase. J. Biol. Chem. 274, 23719-23725. doi: 10.1074/jbc.274.34.23719

Schuster, A., and Schmoll, M. (2010). Biology and biotechnology of Trichoderma. Appl. Microbiol. Biotechnol. 87, 787-799. doi: 10.1007/s00253-010-2632-1

Segata, N., Izard, J., Waldron, L., Gevers, D., Miropolsky, L., Garrett, W. S., et al. (2011). Metagenomic biomarker discovery and explanation. Genome Biol. 12:R60. doi: 10.1186/gb-2011-12-6-r60

Sepehr, M. N., Nasseri, S., Zarrabi, M., Samarghandi, M. R., and Amrane, A. (2012). Removal of Cr (III) from tanning effluent by Aspergillus niger in airlift bioreactor. Sep. Purif. Technol. 96, 256-262. doi: 10.1016/j.seppur.2012.06.013

Skrivanova, V., Skrivan, M., Marounek, M., and Baran, M. (2001). Effect of feeding supplemental copper on performance, fatty acid profile and on cholesterol contents and oxidative stability of meat of rabbits. Arch. Tierernahr. 54, 329339. doi: 10.1080/17450390109381989

Solaiman, S. G., Maloney, M. A., Qureshi, M. A., Davis, G., and D’Andrea, G. (2001). Effects of high copper supplements on performance, health, plasma copper and enzymes in goats. Small Rumin. Res. 41, 127-139. doi: 10.1016/ s0921-4488(01)00213-9

Solisio, C., Lodi, A., Torre, P., Converti, A., and Del Borghi, M. (2006). Copper removal by dry and re-hydrated biomass of spirulina platensis. Bioresour. Technol. 97, 1756-1760. doi: 10.1016/j.biortech.2005.07.018

Stahly, T. S., Cromwell, G. L., and Monegue, H. J. (1980). Effects of the dietary inclusion of copper and(or) antibiotics on the performance of weanling pigs. J. Anim. Sci. 51, 1347-1351. doi: 10.2527/jas1981.5161347x

Sun, X. Y., Liu, L. L., Ma, T. T., Yu, J., Huang, W. D., Fang, Y. L., et al. (2019). Effect of high Cu2 + stress on fermentation performance and copper biosorption of Saccharomyces cerevisiae during wine fermentation. Food Sci. Technol. 39, 19-26. doi: 10.1590/1678-457x.24217

Sun, X. Y., Liu, L. L., Zhao, Y., Ma, T. T., Zhao, F., Huang, W. D., et al. (2016). Effect of copper stress on growth characteristics and fermentation properties of Saccharomyces cerevisiae and the pathway of copper adsorption during wine fermentation. Food Chem. 192, 43-52. doi: 10.1016/j.foodchem.2015.06.107

Virolainen, S., Holopainen, O., Maliarik, M., and Sainio, T. (2019). Ion exchange purification of a silver nitrate electrolyte. Miner. Eng. 132, 175-182. doi: 10. 1016/j.mineng.2018.12.020

Wang, J. Y., and Cui, C. W. (2017). Characterization of the biosorption properties of dormant spores of Aspergillus niger: a potential breakthrough agent for removing Cu2+ from contaminated water. RSC Adv. 7, 14069-14077. doi: 10. 1039/c6ra28694a

Wang, J. Y., Cui, H., Cui, C. W., and Xing, D. F. (2016). Biosorption of copper(II) from aqueous solutions by Aspergillus niger-treated rice straw. Ecol. Eng. 95, 793-799. doi: 10.1016/j.ecoleng.2016.07.019

Wang, W. Y., Sun, J. J., Dong, C. L., and Lian, B. (2016). Biotite weathering by Aspergillus niger and its potential utilisation. J. Soils Sediments 16, 1901-1910. doi: $10.1007 /$ s11368-016-1388-3
Wuana, R. A., and Okieimen, F. E. (2011). Heavy metals in contaminated soils: a review of sources, chemistry, risks and best available strategies for remediation. ISRN Ecol. 2011, 1-20. doi: 10.5402/2011/402647

Xu, D., Wang, H. X., Zhang, Y. Z., Yang, Z. D., and Sun, X. L. (2013). Inhibition of non-toxigenic Aspergillus niger FS10 isolated from Chinese fermented soybean on growth and aflatoxin B-1 production by Aspergillus flavus. Food Control 32, 359-365. doi: 10.1016/j.foodcont.2012.12.013

Yang, H., Huang, X. C., Fang, S. M., Xin, W. S., Huang, L. S., and Chen, C. Y. (2016). Uncovering the composition of microbial community structure and metagenomics among three gut locations in pigs with distinct fatness. Sci. Rep. 6:27427. doi: 10.1038/srep27427

Yang, W., Wang, J., Liu, L., Zhu, X., Wang, X., Liu, Z., et al. (2011). Effect of high dietary copper on somatostatin and growth hormone-releasing hormone levels in the hypothalami of growing pigs. Biol. Trace Elem. Res. 143, 893-900. doi: 10.1007/s12011-010-8904-x

Yang, Y. Z., Misra, B. B., Liang, L., Bi, D. X., Weng, W. H., Wu, W., et al. (2019). Integrated microbiome and metabolome analysis reveals a novel interplay between commensal bacteria and metabolites in colorectal cancer. Theranostics 9, 4101-4114. doi: 10.7150/thno.35186

Zabochnicka-Swiatek, M., and Krzywonos, M. (2014). Potentials of biosorption and bioaccumulation processes for heavy metal removal. Pol. J. Environ. Stud. 23, 551-561.

Zhai, H. X., Gong, L. M., and Ma, Y. X. (2006). A comparison of copper methionine, tribasic copper chloride and copper sulfate as copper sources for swine. J. Anim. Vet. Adv. 5, 623-628.

Zhang, G., Lin, Y., and Wang, M. (2011). Remediation of copper polluted red soils with clay materials. J. Environ. Sci. (China) 23, 461-467. doi: 10.1016/s10010742(10)60431-7

Zhi, M. Y., Tang, P., Liu, Y., He, D., and Zheng, S. X. (2020). Effects of organic copper on growth performance and oxidative stress in mice. Biol. Trace Elem. Res. 194, 455-462. doi: 10.1007/s12011-019-01796-2

Zhou, G. H., Chen, Y. J., Kong, Q., Ma, Y. X., and Liu, Y. (2017). Detoxification of aflatoxin B1 by Zygosaccharomyces rouxii with solid state fermentation in peanut meal. Toxins 9:42. doi: 10.3390/toxins9010042

Zhu, Y. L., Pilon-Smits, E. A. H., Jouanin, L., and Terry, N. (1999). Overexpression of glutathione synthetase in Indian mustard enhances cadmium accumulation and tolerance. Plant Physiol. 119, 73-79. doi: 10.1104/pp.11 9.1 .73

Conflict of Interest: The authors declare that the research was conducted in the absence of any commercial or financial relationships that could be construed as a potential conflict of interest.

Publisher's Note: All claims expressed in this article are solely those of the authors and do not necessarily represent those of their affiliated organizations, or those of the publisher, the editors and the reviewers. Any product that may be evaluated in this article, or claim that may be made by its manufacturer, is not guaranteed or endorsed by the publisher.

Copyright (c) 2021 Zhen, Wang, Gu, Yu, Shahzad, Xu, Gong, Li and Loor. This is an open-access article distributed under the terms of the Creative Commons Attribution License (CC BY). The use, distribution or reproduction in other forums is permitted, provided the original author(s) and the copyright owner(s) are credited and that the original publication in this journal is cited, in accordance with accepted academic practice. No use, distribution or reproduction is permitted which does not comply with these terms. 